\title{
A Thermodynamic Study on Hydration and Dehydration of DNA and RNA -Amphiphile Complexes
}

\section{A Heidari}

Faculty of Chemistry, California South University, 14731 Comet St. Irvine, CA 92604, USA

*Corresponding Author: A Heidari, Faculty of Chemistry, California South University (CSU), 14731 Comet St. Irvine, CA 92604, USA, Tel: +1-775-410-4974; E-Mail: Scholar.Researcher.Scientist@gmail.com

Rec date: Mar 21, 2016; Acc date: Mar 23, 2016; Pub date: Mar 31, 2016

Copyright: (C) 2016 Heidari A. This is an open-access article distributed under the terms of the Creative Commons Attribution License, which permits unrestricted use, distribution, and reproduction in any medium, provided the original author and source are credited.

\section{Opinion}

In the current opinion, we would like to study adhesion of DNA and RNA-amphiphile complexes to non-modified glasses, glasses containing phenylboronic acid (PBA) attached via 3glycidoxypropyltrimethoxysilane (GPTMS) [(PBA-GPTMS-glasses)] and glasses containing grafted dimethyllacrylamide-acrylamide phenylboronic acid (DMAA-AAPBA) copolymer (DMAA-AAPBAglasses). We prepared glasses modified with GPTMS and then attached PBA to them. After that, we modified glasses by (3-mercaptoropyl) trimethoxy silane (MPTMS) and grafted DMAA-AAPBA copolymer to the modified glass plates. For increasing the measuring sensitivity, DNA and RNA-amphiphile complexes were stained with Procion Red HE3B, Red 4GE, Red 510, Red KE3B, Red 120, Red ABO, Red A4G, Red 3B, Red KE3B, Red HE3G, Red 53 L, Red HE3BI, Red E3B, Red CT3B, Red ES3B, Red LHE3B, Red I3B, Red HE3BFC, Red MEB, Red SE3BI, Red 24990, Red SE3B, Red 3BHE and other active and reactive dyes. DNA and RNA-amphiphile complexes stained with Procion Red HE3B, Red 4GE, Red 510, Red KE3B, Red 120, Red ABO, Red A4G, Red 3B, Red KE3B, Red HE3G, Red 53 L, Red HE3BI, Red E3B, Red CT3B, Red ES3B, Red LHE3B, Red I3B, Red HE3BFC, Red MEB, Red SE3BI, Red 24990, Red SE3B, Red 3BHE and other active and reactive dyes formed denser and more stable layer on the copolymer-grafted supports compared onto supports modified with phenylboric acid via a organosilane spacer [1-18]. Adhesion of DNA and RNA-amphiphile complexes to boronate-containing polymer fixed on solid support in different conditions such as $\mathrm{pH}$, precipitation time and different concentrations of glucose (dextrose), fructose (levulose) and galactose were studied.

Furthermore, the internal structure of DNA/RNA-CTAB and DNA/ RNA-DDAB is investigated by X-Ray Diffraction (XRD), EnergyDispersive X-Ray Spectroscopy (EDX) and Small Angel X-Ray Scattering (SAXRS). Hexagonal packing of DNA and RNA was observed for DNA and RNA complexes with Cetyltrimethyl Ammonium Bromide (CTBA) and for Dimethyldioctadecyl Ammonium Bromide (DDAB) complexes is observed lamellar structure. Variations in the internal spacing and degree of long-range ordering are dependent on both surfactant type and concentrations of added salt [19-29]. When we increased the amount of salt into our complexes, we observed that the $\mathrm{d}$ spacing $(\mathrm{d}=2 \Pi / \mathrm{r})$ are increased.

On the other hand, we present a novel method for monitoring isothermal DNA/RNA - Gemini surfactants hydration and dehydration using a sorption microcalorimeter. Gemini surfactant is a name assigned to a family of synthetic amphiphiles surfactants such as: Alkanediyl- $\alpha-\omega$-bis (dimethylammonium bromide) surfactants referred to as $\mathrm{m}-\mathrm{s}-\mathrm{m}$ where $\mathrm{s}$ is the number of Carbon atoms in the polymethylene chains connecting the two $\mathrm{CnH} 2 \mathrm{n}+1 \mathrm{~N}+(\mathrm{CH} 3) 2 \mathrm{Br}-$ moieties [30-38]. We present measurements of isothermal DNA/RNA $+12-s-12$ (with $s=2,4,6,8,10,12,14,16,18,20$ ) complexes at room temperature. This calorimeter provides simultaneous measurement of (a) Water activity (sorption isotherms) and (b) The partial molar enthalpy of water as a function of water uptake. The enthalpy is strongly positive at high water contents. The hydration and dehydration of the DNA/RNA+12-2-12, DNA/RNA+12-4-12, DNA/RNA+12-6-12, DNA/RNA+12-8-12, DNA/RNA+12-10-12, DNA/RNA+12-12-12, DNA/RNA+12-14-12, DNA/RNA+12-16-12, DNA/RNA+12-18-12 and DNA/RNA+12-20-12 (1:1) complexes are exothermic but after incorporation of the first $16.8 \pm 0.1,8.4 \pm 0.1$, $6.3 \pm 0.1,11.7 \pm 0.1,14.3 \pm 0.1,17.5 \pm 0.1,18.8 \pm 0.1,13.7 \pm .0 .1,19.9 \pm 0.1$ and $24.2 \pm 0.1$ water molecules the enthalpy changes sign, respectively. This means that, after these points, the sorption is driven by an entropic rather than enthalpy-entropy effect.

\section{References}

1. Heidari A (2012) A Thesis submitted to the Faculty of the Chemistry. California South University (CSU), Irvine, California, The United States of America (USA) in Fulfillment of the Requirements for the Degree of Doctor of Philosophy $(\mathrm{PhD})$ in Chemistry.

2. Chiang VC, Chan SS (2014) An evaluation of advanced simulation in nursing: A mixed-method study. Collegian 21: 257-265.

3. Incerti S, Champion C, Tran HN, Karamitros M, Bernal M, et al. (2013) Energy deposition in small-scale targets of liquid water using the very low energy electromagnetic physics processes of the Geant4 toolkit. Nuclear Instruments and Methods in Physics Research Section B: Beam Interactions with Materials and Atoms 306: 158-164.

4. Court DS (2004) Between country comparison of a large Caucasian STR database collected as part of the Standardisation in DNA Profiling project. International Congress Series 1261: 62-64.

5. Álvarez-Ros MC, Palafox MA (2016) Simulation of the solid state and the first and second hydration shell of the xanthine oxidase inhibitor allopurinol: Structures obtained using DFT and MP2 methods. Journal of Molecular Structure 1111: 166-179.

6. Jadhao M, Ahirkar P, Joshi R, Kumar H, Ghosh SK (2016) Interaction of aluminum phthalocyanine with aziridinyl quinone in biomimicking micellar microenvironment for the application in photodynamic therapy: Effect of micellar hydration. Journal of Photochemistry and Photobiology A: Chemistry 316: 62-68.

7. Zhou Y, Han H, Naw HPP, Lammy AV, Goh CH, et al. (2016) Real-time colorimetric hydration sensor for sport activities, Materials \& Design 90: 1181-1185.

8. Michot JL, Ferrage E, Delville, Ruiz MJ (2016) Influence of layer charge, hydration state and cation nature on the collective dynamics of interlayer water in synthetic swelling clay minerals. Applied Clay Science 119: 375-384.

9. Papadantonakis GA, Eichler DR, Hamann HA, Harte KA (2016) Effects of Hydration on the Photoionization Threshold Energy of DNA 
Components and on the Activation Barriers for Guanine Methylation by Dimethyl Sulfate. Biophysical Journal 110: 403.

10. Son I, Shek YL, Dubins DN, Chalikian TV (2016) Hydration Changes Accompanying Helix-To-Coil DNA Transitions. Biophysical Journal 110: 4040-4047.

11. Zhong A, Xu W, Zhao J, Xie P, Jia S, et al. (2016) S100A8 and S100A9 Are Induced by Decreased Hydration in the Epidermis and Promote Fibroblast Activation and Fibrosis in the Dermis. The American Journal of Pathology 186: 109-122.

12. Jianwei Du, Bangbang Li, Zhang P, Wang Y (2016) Cationized bovine serum albumin as gene carrier: Influence of specific secondary structure on DNA complexibility and gene transfection. Colloids and Surfaces B: Biointerfaces 143: 37-46.

13. Patra A, Hazra S, Samanta N, Kumar GS, Mitra RK (2016) Micelle induced dissociation of DNA-ligand complexes: The effect of ligand binding specificity. International Journal of Biological Macromolecules 82: 418-424.

14. Chen CC, Lai ZL, Wang GJ, Wu CJ (2016) Polymerase chain reaction-free detection of hepatitis $\mathrm{B}$ virus DNA using a nanostructured impedance biosensor. Biosensors and Bioelectronics 77: 603-608.

15. Wang $\mathrm{X}, \mathrm{Ye} \mathrm{X}$, Zhang $\mathrm{G}$ (2016) Investigation of $\mathrm{pH}$-induced conformational change and hydration of poly(methacrylic acid) investigated by analytical ultracentrifugation. Nanomedicine: Nanotechnology, Biology and Medicine 12: 536-537.

16. Krüger K, Ziegler V, Hartmann C, Henninger C, Thomale J, et al. (2016) Lovastatin prevents cisplatin-induced activation of pro-apoptotic DNA damage response (DDR) of renal tubular epithelial cells. Toxicology and Applied Pharmacology 292: 103-114.

17. Kaushik M, Kaushik S, Roy K, Singh A, Mahendru S, et al. (2016) A bouquet of DNA structures: Emerging diversity. Biochemistry and Biophysics Reports 5: 388-395.

18. Kabir A, Kumar GS (2016) Targeting of 1-Naphthyl acetyl spermine to DNA: A calorimetric and spectroscopic investigation. The Journal of Chemical Thermodynamics 94: 52-60.

19. Wen J, Shen H, Zhai YR, Zhang FS (2016) Simulation of DNA in water/ ethanol mixture. Physica A: Statistical Mechanics and its Applications 450: 515-522.

20. Pascolo L, Bedolla DE, Vaccari L, Venturin I, Cammisuli F, et al. (2016) Pitfalls and promises in FTIR spectromicroscopy analyses to monitor iron-mediated DNA damage in sperm. Reproductive Toxicology 61: 39-46.

21. Bernal MA, Bordage MC,. Brown JMC, Davídková M, Delage E, et al. (2015) Track structure modeling in liquid water: A review of the Geant4DNA very low energy extension of the Geant 4 Monte Carlo simulation toolkit. Physica Medica 31: 861-874.

22. Furusawa H, Nakayama H, Funasaki M, Okahata Y (2016) Kinetic characterization of small DNA-binding molecules interacting with a DNA strand on a quartz crystal microbalance. Analytical Biochemistry 492: $34-42$.

23. Zhao H, Shen K (2016) Microwave-induced inactivation of DNA-based hybrid catalyst in asymmetric catalysis. International Journal of Biological Macromolecule 84: 367-371.

24. Cassina V, Manghi M, Salerno D, Tempestini A, Iadarola V, et al. (2016) Effects of cytosine methylation on DNA morphology: An atomic force microscopy study. Biochimica et Biophysica Acta (BBA) - General Subjects 1860: 1-7.

25. Pratviel G (2016) Porphyrins in complex with DNA: Modes of interaction and oxidation reactions. Coordination Chemistry Reviews 308: 460-477.

26. Green M, Hatter L, Brookes E, Soultanas P, Scott DJ (2016) Defining the Intrinsically Disordered C-Terminal Domain of SSB Reveals DNAMediated Compaction. Journal of Molecular Biology 428: 357-364.

27. Steffensmeier CR, Marky LA (2016) Chapter Sixteen - The Complementarity of the Loop to the Stem in DNA Pseudoknots Gives Rise to Local TAT Base-Triplets. Methods in Enzymology 567: 413-432.

28. Rodrigo Galindo-Murillo and Thomas E. Cheatham III (2016) Chapter 4 - Using Information about DNA Structure and Dynamics from Experiment and Simulation to Give Insight into Genome-Wide Association Studies. In Translational Cardiometabolic Genomic Medicine, Academic Press, Boston.

29. Paul BK, Ghosh N, Mukherjee S (2016) Interaction of an anti-cancer photosensitizer with a genomic DNA: From base pair specificity and thermodynamic landscape to tuning the rate of detergent-sequestered dissociation. Journal of Colloid and Interface Science 470: 211-220.

30. Datto M, Lundblad RL (2016) DNA, RNA Chemical Properties (Including Sequencing and Next-Generation Sequencing). In Encyclopedia of Cell Biolog, Academic Press, Waltham.

31. Pruchnik H, Kral T, Poradowski D, Pawlak A, Drynda A, et al. (2016) New cytotoxic butyltin complexes with 2-sulfobenzoic acid: Molecular interaction with lipid bilayers and DNA as well as in vitro anticancer activity. Chemico-Biological Interactions 243: 107-118.

32. Mao H, Saha M, Aldrete ER, Sherman MB, Woodson M, et al. (2016) Structural and Molecular Basis for Coordination in a Viral DNA Packaging Motor. Cell Reports 14: 2017-2029.

33. Olsen CM, Shikiya R, Ganugula R, Steffensmeier CR, Khutsishvili I, et al. (2016) Application of differential scanning calorimetry to measure the differential binding of ions, water and protons in the unfolding of DNA molecules. Biochimica et Biophysica Acta (BBA) - General Subjects 1860: 990-998.

34. Perera RT, Fleming AM, Peterson AM, Heemstra JM, Burrows CJ,et al. (2016) Unzipping of A-Form DNA-RNA, A-Form DNA-PNA, and BForm DNA-DNA in the a-Hemolysin Nanopore. Biophysical Journal 110: 306-314.

35. Sushko ML, Thomas DG, Pabit SA, Pollack L, Onufriev AV, et al. (2016) The Role of Correlation and Solvation in Ion Interactions with B-DNA. Biophysical Journal 110: 315-326.

36. Jitrakorn S, Arunrut N, Sanguanrut P, Flegel TW, Kiatpathomchai W, et al. (2016) In situ DIG-labeling, loop-mediated DNA Amplification (ISDL) for highly sensitive detection of infectious hypodermal and hematopoietic necrosis virus (IHHNV). Aquaculture 456: 36-43.

37. Ilyina MG, Khamitov EM, Ivanov SP, Mustafin AG, Khursan SL (2016) Anions of uracils: N1 or N3? That is the question. Computational and Theoretical Chemistry 1078: 81-87.

38. Nawaz A, Farooq M, Ahmad R, Basra SMA, Lal R (2016) Seed priming improves stand establishment and productivity of no till wheat grown after direct seeded aerobic and transplanted flooded rice. European Journal of Agronomy 76: 130-137.
This article was originally published in a special issue, entitled: "Design of Biosensors", Edited by Dr. Eduardo De Faria Franca, Federal University of Uberlandia 